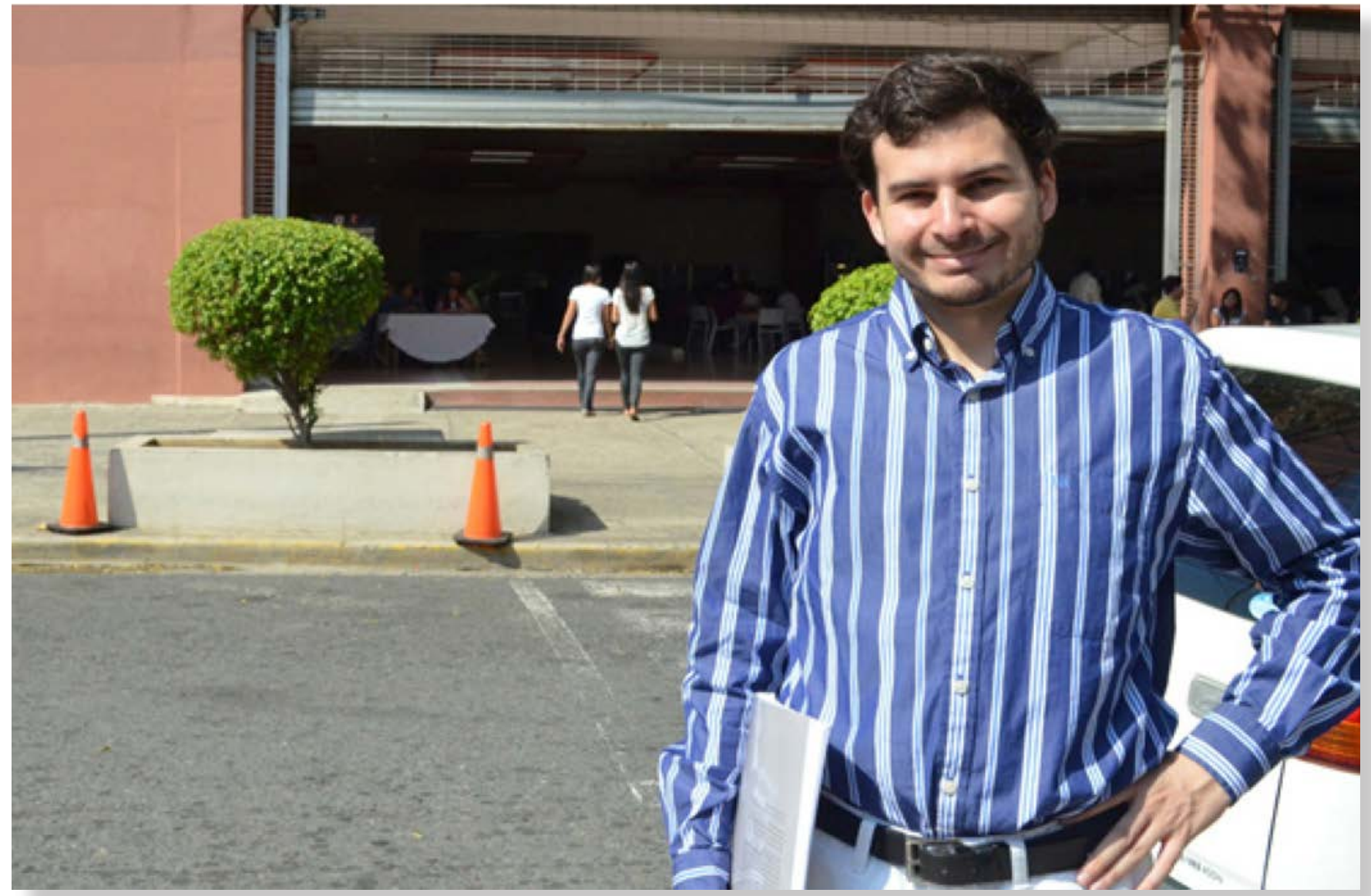

\title{
Reseña del libro Cómo redactar un paper. La escritura de artículos científicos ${ }^{1}$
}

Enrique Sánchez Costa²

\section{Palabras claves}

Redacción académica, artículo científico, paper

\section{5} ntre los géneros discursivos del ámbito científicoacadémico pocos son tan relevantes para el profesor de universidad como el artículo científico (o, en préstamo del inglés: el paper). Como la neurona en el cuerpo humano, el paper es la célula básica de transmisión del conocimiento en el mundo académico. A través de este molde genérico los científicos y académicos de todo el mundo -los scholars- cuestionan el saber previo, dialogan con sus colegas y presentan sus aportaciones.

\footnotetext{
${ }^{1}$ Ramírez, Silvia. (2013). Cómo redactar un paper: La escritura de artículos científicos. Noveduc: Buenos Aires.

2 Enrique Sánchez Costa: Licenciado en Humanidades porla Universidad Pompeu Fabra (UPF). Magíster en Literatura comparada por la Universidad Autónoma de Barcelona (UAB). Doctor en Humanidades por la UPF (Premio Extraordinario de Doctorado, 2012). Profesor a Tiempo Completo y Coordinador del Departamento de Español de la PUCMM (CSTA). Para contactar: enriquesanchez@pucmm.edu.do
} 
De ahí que, para todo profesor universitario, sea esencial conocer las particularidades del artículo científico como género: su estructura textual global (la organización esquemática del texto), su registro, su tono, la función que desempeña en la comunidad, su destinatario, etcétera. El libro que reseñamos, Cómo redactar un paper: la escritura de artículos científicos (2013), escrito por la lingüista argentina Silvia Ramírez Gelbes, arroja luz sobre un tema que, pese a su importancia, a veces se percibe en el ámbito académico con un halo de misterio: el misterio de lo desconocido. Así como no comprende ni disfruta del mismo modo una ópera, un musical, o una película de cine negro quien conoce las convenciones del género y quien las ignora, la comprensión y la creación exitosa de un paper requieren un conocimiento de las estructuras y formas propias de esa clase de texto. Y es que entender la contextura propia de un género permite una lectura más anticipadora, más abarcadora, más selectiva y, por tanto, más atinada y eficaz. En el ámbito de la producción textual, posibilita anticipar las expectativas de la audiencia y adecuar las estrategias textuales para satisfacerlas.

Como expresa la autora del libro, "un artículo de investigación es, por una parte, un aparato erudito que pretende ofrecer un aporte a la disciplina científica en la que se inserta y, por la otra, un aparato retórico que busca persuadir al lector de la legitimidad de ese aporte" (p.13). En este sentido, el libro reseñado aborda las estrategias discursivas que arman el artefacto retórico que constituye todo paper, cuya finalidad es la de comunicar unos conocimientos con la máxima claridad y fuerza persuasiva.

De ahí que, lejos de limitarse a los modos de expresión narrativo, descriptivo y expositivo, el artículo científico acoja también los modos argumentativos y dialógico. De hecho, todo paper dialoga de forma implícita y explícita con la comunidad científica, incorporando la voz ajena a través de la cita directa e indirecta.

El primero de los cuatro capítulos del libro, "El texto escrito", sobrevuela los elementos y los procesos que acompañan la creación de cualquier texto escrito. En cuanto a las características del texto (palabra que proviene del latín textus: tejido, entramado de hilos), la autora recalca las propiedades de coherencia y cohesión, que aseguran la articulación unitaria del texto en todos sus niveles estructurales. Para lograr tal unidad se explican diversos mecanismos textuales (referencia, sustitución, elipsis...), así como el uso adecuado de los marcadores del discurso, que guían las inferencias para comprender los enunciados. En cuanto a la producción del texto, y siguiendo a $\mathrm{D}$. Cassany, se destacan tres momentos en el proceso de escritura: la planificación, la redacción propiamente dicha y la revisión.
Un proceso cuyos tres momentos, en un género tan demandante como el artículo científico, son más necesarios que nunca.

En el segundo capítulo, "El género", se encuadra el artículo científico dentro de los géneros del discurso académico-científico (entre los que se encuentran el resumen, la reseña crítica, la ponencia o la tesis doctoral). Y, a su vez, se integra el conjunto en el marco teórico de los géneros discursivos, desarrollado por Bajtín, cuyas raíces se remontan ya a la clasificación de géneros literarios que estableció Aristóteles en su Poética. Llama la atención, en todo caso, que la autora espere hasta la página 82 , casi a mitad del libro, para explicar la estructura del artículo científico (que es, al cabo, el tema que el título del libro prometía abordar).

El tercer capítulo, "La subjetividad", el más original y perspicaz del libro, analiza la presencia del enunciador en el texto, así como la imagen -el ethos- que este proyecta de sí mismo en el discurso, por medio de diversas opciones expresivas. Entre los elementos que perfilan esa imagen se encuentra el estilo, hilvanado a través de las elecciones formales (léxicas, estructurales, retóricas y rítmicas) del autor. También es relevante el modo en que aparecen en el discurso los agentes del intercambio (enunciador y destinatario).

Como explica la autora, el enunciador podrá graduar la modalización: el grado de certeza o cautela que el propio discurso manifiesta en relación con sus aseveraciones.

De esta manera, algunos autores atenúan sus afirmaciones con el fin de mostrar humildad y deferencia hacia el juicio del destinatario; otros, en cambio, optan por intensificarlas, para recalcar el compromiso con lo que se dice.

En el mismo capítulo se apunta que el ethos que trata de dibujar el autor de un paper buscará crear casi siempre un efecto de cientificidad, objetividad y ponderación. De ahí que se borren a menudo las huellas del sujeto enunciador; o que se avance con mucho tiento, reasegurando el terreno que se transita a través del metatexto: el texto que habla del propio texto, que define sus objetivos y organización, remite a afirmaciones ya enunciadas en el artículo, etcétera. Ese comedimiento se observará con frecuencia en la cita de la voz ajena, en la que la cortesía suele atemperar incluso los momentos de disenso y polémica. De hecho, es habitual que, en todos los géneros del discurso académico-científico, convivan tanto el encomio como la crítica de diversos trabajos de los colegas del campo de estudio. De lo contrario no podríamos hablar de comunidad académica, pues esta requiere la interacción, la convivencia de una pluralidad de pareceres, a menudo encontrados. 


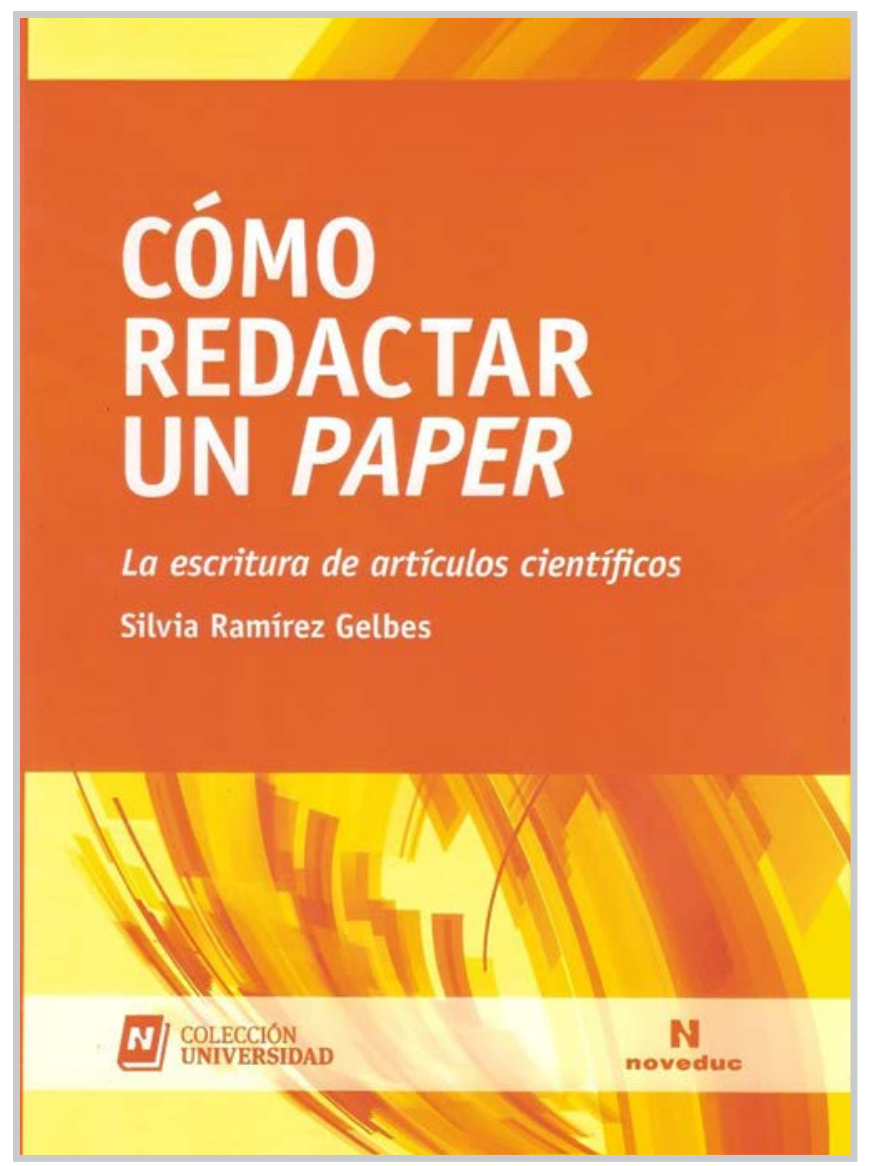

El cuarto y último capítulo, "Los problemas concretos", se focaliza en diversas dificultades que puede encontrar quien escribe artículos científicos. Entre ellas, se tratan cuestiones de puntuación, el empleo del gerundio, el uso y abuso de la terminología específica (tecnolecto), la estructura de la oración o la organización de los párrafos. También se atienden a otras cuestiones más específicas del género académico-científico, como son el uso de notas al pie de página y de referencias bibliográficas, la posibilidad de incluir gráficos e imágenes, o el registro adecuado -formal, normativo y diáfanoque deberían adoptarse en este género discursivo. Se trata, en líneas generales, de un capítulo que alterna indicaciones luminosas con otras más marginales o incluso innecesarias.

Entre los méritos del libro que reseñamos descuella la claridad de su estructuración, que es lógica y didáctica. En este sentido, cabe destacar los ejercicios que se proponen al final de cada uno de los capítulos (con sus respuestas) y que pueden resultar de mucha utilidad para el trabajo en el aula. Además, todas las explicaciones teóricas están aderezadas de numerosos ejemplos, que la autora ha tomado de sus cursos de técnicas de redacción y de escritura académica. Ramírez Gelbes, doctora en lingüística y profesora de la Universidad de Buenos Aires, despliega todos sus conocimientos lingüísticos en un libro sólido, fundamentado

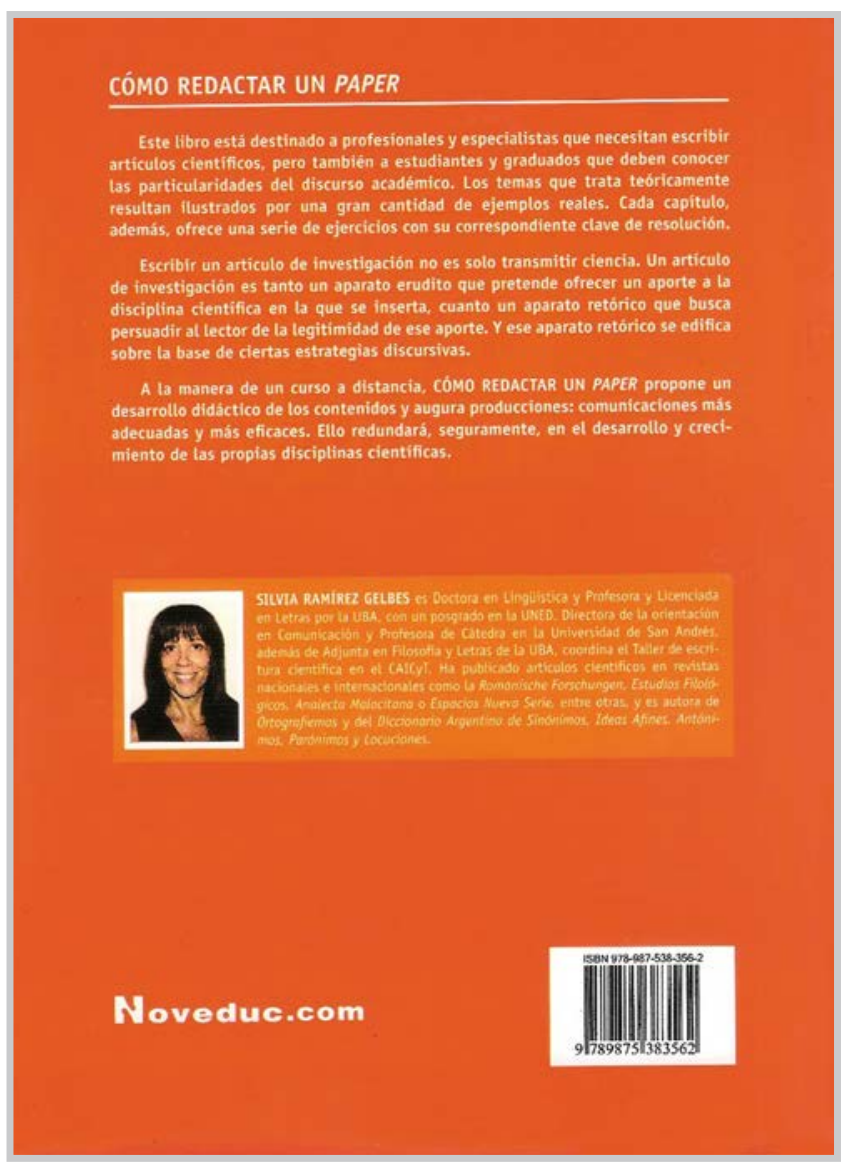

y abarcador, que se propone atender no sólo al género del artículo científico y sus aledaños, sino también al mismo proceso de escritura, así como a las dificultades que acechan al creador y al lector de artículos científicos.

Ahora bien, lo que para algunos sea una fortaleza del libro es, a mi juicio, su mayor debilidad: el abuso de jerga lingüística y, en general, de indicaciones circunstanciales respecto al tema tratado. Acaso el libro ganara en eficacia si se condensaran, en menos páginas, las características y exigencias primordiales del género. Con todo, Cómo redactar un paper: la escritura de artículos científicos, ofrece al interesado muchas páginas provechosas, tanto a nivel personal como para la preparación de materiales de clase. Además, un libro como este conlleva siempre un aldabonazo saludable: el apremio a que en la Universidad, esa "casa donde se busca la verdad propia de la persona humana" (Benedicto XVI, 2011), se potencie sin tregua la investigación. Esta es vital para la ciencia, la tecnología, la industria; y, sobre todo, para que la docencia no se anquilose; para que incorpore los últimos hallazgos en el campo de estudio y, a su vez, espolee a docentes y alumnos a realizar sus propios aportes a la comunidad académica y científica. Así, docencia e investigación se potencian mutuamente, en un círculo virtuoso que redunda en beneficio de alumno y profesor, de la universidad y la sociedad en su conjunto. 